\title{
Impact of immunosuppressants on SARS-CoV-2 infection in elderly patients with inflammatory bowel disease
}

\author{
Margalida Calafat ${ }^{1,2}$ (1) Carlos González-Muñoza ${ }^{3} \cdot$ Marta Fortuny $^{1} \cdot$ Cristina Roig $^{3} \cdot$ Anna Calm $^{1}$. \\ Antonio Mombiela $^{3} \cdot$ Fiorella Cañete $^{1,2}(1) \cdot$ Federico Bertoletti $^{3} \cdot$ Laura González-González $^{1} \cdot$ Marta Teller-Martín $^{3}$. \\ Jordi Gordillo ${ }^{3}$ Míriam Mañosa ${ }^{1,2}$ (D) Esther Garcia-Planella ${ }^{3}\left(\mathbb{D} \cdot\right.$ Eugeni Domènech $^{1,2,4}$ (])
}

Received: 25 May 2021 / Accepted: 16 June 2021 / Published online: 23 June 2021

(c) The Author(s), under exclusive licence to Springer Nature Switzerland AG 2021

\begin{abstract}
Background Older age has been reported as a risk factor for severe SARS-CoV-2 disease (COVID-19). The impact of immunosuppressants (IMS) on COVID-19 is still under debate.

Aim To describe the incidence and severity of COVID-19 in elderly patients with inflammatory bowel disease (IBD) in relation to the use of IMS.

Methods IBD patients over 65 years of age were selected and grouped in terms of IMS use. Confirmed COVID-19, adherence to IST, comorbidities and concomitant non-IBD-related treatments between 1st of March 2020 to 1st of March 2021 were recorded.

Results Out of 418 patients included, 89 (21.3\%) were on IMS. Thirty-two patients (7.7\%) had COVID-19, 7 of whom were on IMS (7.6\% not on IMS vs. $7.9 \%$ on IMS; $P=0.933)$ and 7 (22\%) patients died.

Conclusions Incidence of COVID-19 among elderly IBD patients was similar to that reported in the background population, regardless of the use of IMS.
\end{abstract}

Keywords Elderly $\cdot$ Inflammatory bowel disease $\cdot$ COVID-19 $\cdot$ Immunosuppressants · Thiopurines

\section{Introduction}

In December 2019, an epidemic of a new coronavirus known as severe acute respiratory syndrome coronavirus 2 (SARSCoV2) broke out in Wuhan (China). In Spain, it was not until March that the SARS-CoV2 became widespread. This virus can cause a severe form of disease with a poor prognosis and is commonly known as coronavirus disease or COVID-19. Although most cases are mild or even asymptomatic, the

Eugeni Domènech

eugenidomenech@gmail.com

1 Department of Gastroenterology, Hospital Universitari Germans Trias i Pujol, Badalona, Catalonia, Spain

2 Centro de Investigación Biomédica en Red de Enfermedades Hepáticas y Digestivas (CIBEREHD), Madrid, Spain

3 Department of Gastroenterology, Hospital de la Santa Creu i Sant Pau, Barcelona, Spain

4 Gastroenterology and Hepatology Department, Hospital Universitari Germans Trias I Pujol, Carretera del Canyet s/n, 08916 Badalona, Catalonia, Spain
SARS-CoV-2 infection can induce various clinical symptoms, including severe forms featuring respiratory failure with reported fatality rates of up to $7 \%$ [1]. A number of epidemiologic features have been associated with a worse COVID-19 prognosis, including active smoking, male gender, older age and certain comorbidities, such as arterial hypertension, diabetes, cardiovascular and respiratory diseases [2].

Available data on the susceptibility of IBD patients to the development of COVID-19 suggest that IBD itself does not affect the risk of developing a SARS-CoV-2 infection, nor does it worsen its prognosis when compared to the general population. Preliminary studies from China and subsequently, from Italy, reported no cases of complicated SARSCoV2 infections among IBD patients [3, 4]. Subsequently, a single-center Spanish study and a collaborative French and Italian study reported a similar incidence of COVID-19 in IBD patients and in the general background population [5, 6]. Finally, in another single-center study in Madrid, the observed incidence of COVID-19 in a cohort of 850 IBD patients was $10 \%$, with almost $80 \%$ presenting mild clinical 
symptoms and only one death [7]. Immunosuppressive therapies in IBD can be a double-edged sword in relation to COVID-19. Given the documented increase in the risk of severe viral infections among IBD patients on IMS (thiopurines or methotrexate) [8], an increased risk of SARS-CoV-2 infection, and even a worse prognosis for COVID-19, can be expected.

Elderly IBD patients are increasing in number (accounting for more than $10 \%$ of the IBD population) due to both elderly onset cases and long-lasting IBD. Elderly IBD patients tend to have a higher number of chronic comorbidities, polypharmacy and a worse safety profile for immunosuppressive treatments [9]. In Spain, among the 203,715 cases of COVID-19 reported during the first wave of the pandemic, 105,743 patients $(51.9 \%)$ were over 60 years of age, of whom 15,115 (14.3\%) died [10]. Since then, 685,937 new cases were diagnosed until 21st April 2021, with 45,309 COVID-19-related deaths (6.6\%) [11]. However, no studies focused specifically on elderly IBD patients and the impact of IMS on SARS-CoV-2 infection have been published. Therefore, we aim to describe and compare the incidence of COVID-19 among elderly IBD patients, particularly with regard to the use of IMS.

\section{Materials and methods}

This is an observational, retrospective cohort study performed at two referral IBD centers in the Barcelona area. All IBD patients over 65 years of age were identified from the local IBD databases. Patients were assigned to one of two groups depending on the use of IMS (thiopurines or methotrexate) during the study period. Patients treated with biological therapies (in monotherapy or in combination), JAK inhibitors or calcineurin inhibitors were excluded. Patients' clinical information related to IBD, SARS-CoV-2 infection and comorbidities was obtained from the local registry. In order to avoid missing PCR positive SARS-CoV-2 infection, an active search in the primary care database of the Catalan Institute of Health accessible from the electronic medical record of every patient, as well as the emergency and hospital discharge reports, was carried out. All patients were followed up from March 2020 (the beginning of the pandemic in Catalonia) to March 2021 (the beginning of the vaccination campaign in the elderly). Data collected included: demographic data, IBD-related clinical data, comorbidities, smoking habits and SARS-CoV-2-related information (hospital and intensive care unit admittance, thromboembolic, cardiological and neurological complications and death).

IMS was defined as the use of thiopurines or methotrexate for at least 1 month before the beginning of the study period. Confirmed COVID-19 was defined, in line with the World Health Organization definition, as a symptomatic
SARS-CoV-2 infection (positive protein chain reaction test) during the follow-up period.

The study was approved by the Ethics Committees at both centers. All patients signed an informed consent form to participate in the local database.

Statistical analysis was performed with the usual descriptive and comparative methods. A logistic regression analysis was performed to identify risk factors for SARS-CoV2 infection or hospitalization.

\section{Results}

Out of 477 IBD elderly patients, 418 (87.6\%) patients were included and the $59(12.4 \%)$ patients who were on biological treatment were excluded. The baseline characteristics of included patients are shown in Table 1. From the whole cohort, 89 out of 418 patients $(21.3 \%)$ were on IMS (86 patients on thiopurines and three on methotrexate). Median time on IMS at the beginning of the pandemic was 121 months (IQR, 60-162). Regarding COVID-19-related risk factors for a poor prognosis, both groups were similar. Of note, almost two-thirds of patients had arterial hypertension, one-third suffered from dyslipaemia, one-fifth from cardiovascular diseases, and one-fifth from diabetes. In fact, 134 patients $(32.0 \%)$ presented at least one of the aforementioned comorbidities and $173(41.4 \%)$ patients more than one.

In the whole cohort, COVID-19 was confirmed in 32 patients (7.7\%), 7 of whom were on IMS (six patients on azathioprine and one on methotrexate) (Table 2). Seventeen patients $(53.1 \%)$ required hospital admittance, one of them in the intensive care unit. Four patients (one on IMS) developed SARS-CoV-2-related complications and seven patients (21.9\%) died (one on IMS). The resulting rate of confirmed COVID-19 was $7.9 \%$ among IMS users and $7.6 \%$ among non-users $(P=0.933)$.

In the multivariate regression analysis, arterial hypertension was the only risk factor for COVID-19 (OR 5.703, 95\% IC 1.135-28.658; $P=0.035)$. Additionally, arterial hypertension (OR 9.976, 95\% IC 1.463-68.024; $P=0.019$ ), cardiovascular disease (OR 3.407, 95\% IC 1.137-10.207; $P=0.029$ ) and chronic renal disease (OR $3.410,95 \%$ IC $1.089-10.671 ; P=0.035)$ were risk factors for hospitalization.

\section{Discussion}

This is the first study focusing on the incidence of COVID19 in elderly IBD patients. In addition to the advanced age of our study population, we also assessed the impact of IMS on the risk for developing and on the prognosis of this 
Table 1 Clinical and demographic characteristics of the entire cohort

\begin{tabular}{|c|c|c|c|c|}
\hline & $\begin{array}{l}\text { Whole cohort } \\
n=418\end{array}$ & $\begin{array}{l}\text { Patients on IST } \\
n=89\end{array}$ & $\begin{array}{l}\text { Patients without } \\
\text { IST } n=329\end{array}$ & $P$ value \\
\hline Median age, years (IQR) & $73(69-78)$ & $71(68-76)$ & $73(69-79)$ & ns \\
\hline Female, $n(\%)$ & $200(47.8)$ & $47(52.8)$ & $153(46.5)$ & ns \\
\hline \multicolumn{5}{|l|}{ IBD type, $n(\%)$} \\
\hline Crohn's disease & $117(28.0)$ & $52(58.4)$ & $65(19.7)$ & 0.001 \\
\hline Ulcerative colitis & $290(69.4)$ & $36(40.4)$ & $254(77.2)$ & \\
\hline Unclassified colitis & $11(2.6)$ & $1(1.1)$ & $10(3.0)$ & \\
\hline Perianal disease, $n(\%)$ & $29(6.9)$ & $11(12.4)$ & $18(5.5)$ & 0.023 \\
\hline Extraintestinal manifestations, $n(\%)$ & $45(10.8)$ & $19(21.3)$ & $26(7.9)$ & 0.001 \\
\hline Familial IBD, $n(\%)$ & $43(10.3)$ & $13(14.6)$ & $30(9.1)$ & ns \\
\hline Active smoker, $n(\%)$ & $19(4.8)$ & $7(8.1)$ & $12(3.9)$ & ns \\
\hline \multicolumn{5}{|l|}{ Comorbidities, $n(\%)$} \\
\hline Cardiovascular disease & $91(21.8)$ & $14(15.7)$ & $77(23.4)$ & ns \\
\hline Arterial hypertension & $259(62.0)$ & $59(66.3)$ & $200(60.8)$ & ns \\
\hline Diabetes & $98(23.4)$ & $14(15.7)$ & $84(25.5)$ & ns \\
\hline Dyslipaemia & $145(34.7)$ & $23(25.8)$ & $122(37.1)$ & 0.048 \\
\hline COPD & $61(14.6)$ & $17(19.1)$ & $44(13.4)$ & ns \\
\hline CRD & $46(11.0)$ & $6(6.7)$ & $40(12.2)$ & ns \\
\hline Anti-hypertensive treatment, $n(\%)$ & $240(57.4)$ & $55(61.8)$ & $185(56.2)$ & ns \\
\hline$>1$ anti-hypertensive drug, $n(\%)$ & $117(28.0)$ & $25(28.1)$ & $92(27.9)$ & \\
\hline ACEI & $118(28.2)$ & $27(30.3)$ & $91(27.7)$ & \\
\hline ARA-II & $70(16.7)$ & $15(16.9)$ & $55(16.7)$ & \\
\hline Calcium antagonist & $51(12.2)$ & $11(12.4)$ & $40(12.1)$ & \\
\hline Diuretics & $104(24.9)$ & $26(29.2)$ & $78(23.7)$ & \\
\hline Beta-blocker & $8(1.9)$ & $1(1.1)$ & $7(2.1)$ & \\
\hline Anti-diabetic treatment, $n(\%)$ & $83(19.9)$ & $11(12.4)$ & $72(21.9)$ & 0.046 \\
\hline$>1$ drug treatment, $n(\%)$ & $27(6.5)$ & $7(7.9)$ & $20(6.1)$ & ns \\
\hline Insulin & $35(8.4)$ & $7(7.9)$ & $28(8.5)$ & $\mathrm{ns}$ \\
\hline Metformin & $46(11.0)$ & $5(5.6)$ & $41(12.5)$ & ns \\
\hline Gliclazide & $15(3.6)$ & $2(2.2)$ & $13(4.0)$ & ns \\
\hline Statin treatment, $n(\%)$ & $145(34.7)$ & $23(25.8)$ & $122(37.1)$ & 0.048 \\
\hline Anticoagulant treatment, $n(\%)$ & $55(13.2)$ & $8(9.0)$ & $47(14.3)$ & $\mathrm{ns}$ \\
\hline Anti-platelet treatment, $n(\%)$ & $74(17.7)$ & $13(14.6)$ & $61(18.5)$ & \\
\hline
\end{tabular}

$C O P D$ chronic obstructive pulmonary disease, $C R D$ chronic renal disease, $I B D$ inflammatory bowel disease; $A C E I$ angiotensin converting enzyme inhibitor; ARA-II angiotensin II receptor antagonist; IQR interquartile range; $I S T$ immunosuppressive treatment; $n s$ non-significant viral infection since thiopurines are firmly associated with a higher risk of viral infections [8] (much more so than antiTNF agents).

We observed an incidence of COVID-19 of $7.7 \%$ in our cohort of elderly IBD patients. This figure is quite similar to that of the background elderly population; in fact, the cumulative incidence of confirmed SARS-CoV-2 infection in Catalonia among people over 60 years during the study period was $6.6 \%$ [12]. Moreover, and contrary to our expectations, we did not observe a significant difference in the incidence of confirmed COVID-19 between IMS users and non-users. Indeed, non-users of IMS presented a higher rate of SARS-CoV2 infection-related complications and death. Recently, the use of thiopurines, either in monotherapy or in combination with anti-TNF agents, was independently associated with an increased risk of severe COVID-19 as defined by intensive care unit admission, ventilator use and/ or death [13]; however, this association was not observed in other studies [14, 15]. Of note, aminosalicylates (which are not immunosuppressive and are commonly used in IBD) have also been associated with a worse COVID-19 prognosis [13].

During the same time period, the COVID-19-associated mortality rate among unselected individuals over 60 years of age in Catalonia was $16.1 \%$ [12]; the mortality rate in our IBD cohort was slightly higher (22\%). Noteworthy, only one out of seven patients who died was on IMS. This reinforces the idea that older age, but not the use of IMS, is associated 
Table 2 Characteristics of elderly IBD patients developing COVID-19 $(n=32)$

\begin{tabular}{|c|c|c|c|}
\hline Confirmed COVID-19 patients & $\begin{array}{l}\text { Whole cohort } \\
N=32\end{array}$ & $\begin{array}{l}\text { Not IMS } \\
N=25\end{array}$ & $\begin{array}{l}\text { IMS } \\
N=7\end{array}$ \\
\hline Age, years (IQR) & $76(71-79)$ & $73(69-79)$ & $71(68-76)$ \\
\hline Male gender, $n(\%)$ & $21(65.6)$ & $15(71.4)$ & $6(28.6)$ \\
\hline \multicolumn{4}{|l|}{ IBD type, $n(\%)$} \\
\hline Crohns' disease & $11(34.4)$ & $5(45.5)$ & $6(54.5)$ \\
\hline Ulcerative colitis & $21(65.6)$ & $20(95.2)$ & $1(4.8)$ \\
\hline Active smoker, $n(\%)$ & $0(0.0)$ & - & - \\
\hline SARS-CoV2 infection complications, $n(\%)$ & $4(12.5)$ & $3(75.0)$ & $1(25.0)$ \\
\hline SARS-CoV2-related death, $n(\%)$ & $7(21.9)$ & $6(85.7)$ & $1(14.3)$ \\
\hline Arterial hypertension, $n(\%)$ & $28(87.5)$ & $21(75.0)$ & $7(25.0)$ \\
\hline Diabetes, $n(\%)$ & $13(40.6)$ & $11(84.6)$ & $2(15.4)$ \\
\hline Chronic renal disease, $n(\%)$ & $6(18.8)$ & $4(66.7)$ & $2(33.3)$ \\
\hline $\mathrm{COPD}, n(\%)$ & $5(15.6)$ & $3(60.0)$ & $4(40.0)$ \\
\hline Dyslipaemia, $n(\%)$ & $8(25.0)$ & $8(100.0)$ & $0(0.0)$ \\
\hline Cardiovascular disease, $n(\%)$ & $11(34.4)$ & $7(36.6)$ & $4(36.4)$ \\
\hline Anti-hypertensive treatment, $n(\%)$ & $25(78.1)$ & $18(72.0)$ & $7(28.0)$ \\
\hline ACEI & 7 (21.9) & $4(57.1)$ & $3(42.9)$ \\
\hline ARA-II & $8(25)$ & $7(87.5)$ & $1(12.5)$ \\
\hline Calcium antagonist & $6(18.8)$ & $5(83.3)$ & $1(16.7)$ \\
\hline Diuretics & $13(40.6)$ & $10(76.9)$ & $3(23.1)$ \\
\hline Beta-blocker & $3(9.4)$ & $2(66.7)$ & $1(33.3)$ \\
\hline Anti-diabetic treatment, $n(\%)$ & $10(31.3)$ & $9(90.0)$ & $1(10.0)$ \\
\hline Statin treatment, $n(\%)$ & $8(25)$ & $8(100)$ & $0(0.0)$ \\
\hline Anticoagulant treatment, $n(\%)$ & $7(21.9)$ & $6(85.7)$ & $1(14.3)$ \\
\hline Anti-platelet treatment, $n(\%)$ & $5(15.6)$ & $5(100)$ & $0(0.0)$ \\
\hline \multicolumn{4}{|l|}{ Type of IMS, $n(\%)$} \\
\hline Thiopurine/Methotrexate & - & - & $6(86) / 1(14)$ \\
\hline Time on IMS, months (IQR) & & & $120(40-172)$ \\
\hline
\end{tabular}

$C O P D$ chronic obstructive pulmonary disease; $I B D$ inflammatory bowel disease; $A C E I$ angiotensin converting enzyme inhibitor; ARA-II angiotensin II receptor antagonist; IMS immunosuppressant with a poor prognosis, in agreement with previous studies [4]. Beyond the effect of age, the elderly present a higher incidence of comorbidities and this also may worsen the outcomes of COVID-19. In agreement with previous studies, cardiovascular disease, chronic renal disease and arterial hypertension were associated with a higher risk of hospital admission. Most of the patients in our cohort had one comorbidity and $41 \%$ of them more than one; this high rate of comorbidities may explain the slightly increase in mortality rate as compared to our background elderly population.

The present study has some additional limitations. Although we carried out an active search so as not to miss cases of confirmed COVID-19 patients, the confirmation of laboratory tests was only performed in more symptomatic cases, particularly during the first wave of the pandemic. Moreover, we excluded those patients on biologicals as elderly patients are treated less often with biological agents and, if so, there is a trend towards using drugs that are associated with fewer immunosuppressive effects, such as vedolizumab and ustekinumab.

In conclusion, the incidence of confirmed COVID-19 during the first year of the pandemic in elderly patients with IBD was similar to that reported in the age-adjusted background population. In this population, SARS-CoV2 infection was associated with a bad prognosis, a high rate of related complications and mortality, particularly in patients with comorbidities and regardless of the use of IMS.

Author contributions MC designed the study, constructed the study database, performed statistical analyses, interpreted the results, and drafted the manuscript. ED designed the study, interpreted the results, and drafted the manuscript. All the remaining authors collected data and critically reviewed the manuscript. All authors approved the final version of the article.

Funding The study received no funding. 


\section{Declarations}

Conflict of interest MC has served as a speaker or has received research or education funding or advisory fees from Takeda, Janssen, Faes Farma, and MSD; CG-M has served as speaker or has received research or education funding or advisory fees from Norgine, Janssen, Ferring; FC has served as a speaker or has received research or education funding or advisory fees from Takeda, Janssen, MSD, and Ferring; MM has served as a speaker or has received research or education funding or advisory fees from FAES, Ferring MSD, AbbVie, Takeda and Janssen; EG-P has served as a speaker and has received research and educational funding and advisory fees from MSD, AbbVie, Takeda, Kern Pharma, Pfizer, Janssen, Ferring, Shire Pharmaceuticals, and Tillots; ED has served as a speaker and has received research and educational funding and advisory fees from MSD, AbbVie, Takeda, Celltrion, Samsung Bioepis, Kern Pharma, Pfizer, Janssen, Celgene, Adacyte Therapeutics, Otsuka Pharmaceuticals, Ferring, Shire Pharmaceuticals, Tillots, Thermofisher, Grifols, Gilead, Roche and Gebro. The remaining authors declared no conflicts of interest.

Ethical approval The study was approved by the Ethics Committees at both centers.

Informed consent All patients signed an informed consent form to participate in the local database.

\section{References}

1. Onder G, Rezza G, Brusaferro S (2020) Case-fatality rate and characteristics of patients dying in relation to COVID-19 in Italy. JAMA 323:1775-1776 (Erratum in: JAMA. 2020; 323:1619)

2. Zheng Z, Peng F, Xu B et al (2020) Risk factors of critical and mortal COVID-19 cases: a systematic literature review and metaanalysis. J Infect 81:e16-e25

3. Mao R, Liang J, Shen J et al (2020) Implications of COVID-19 for patients with pre-existing digestive diseases. Lancet Gastroenterol Hepatol 5:425-427 (Erratum in: Lancet Gastroenterol Hepatol. 2020;5:e6)

4. Norsa L, Indriolo A, Sansotta N, Cosimo P, Greco S, D’Antiga L (2020) Uneventful course in patients with inflammatory Bowel disease during the severe acute respiratory syndrome Coronavirus 2 outbreak in Northern Italy. Gastroenterology 159:371-372

5. Allocca M, Fiorino G, Zallot $C$ et al (2020) Incidence and patterns of COVID-19 among inflammatory bowel disease patients from the Nancy and Milan cohorts. Clin Gastroenterol Hepatol $18: 2134-2135$
6. Taxonera C, Sagastagoitia I, Alba C et al (2020) 2019 novel coronavirus disease (COVID-19) in patients with inflammatory bowel diseases. Aliment Pharmacol Ther 52:276-283

7. Guerra I, Algaba A, Jiménez L et al (2021) Incidence, clinical characteristics, and evolution of SARS-CoV-2 infection in patients with inflammatory bowel disease: a single-center study in Madrid, Spain. Inflamm Bowel Dis 27:25-33

8. Wisniewski A, Kirchgesner J, Seksik P et al (2019) Increased incidence of systemic serious viral infections in patients with inflammatory bowel disease associates with active disease and use of thiopurines. United Eur Gastroenterol J 8:303-313

9. Calafat M, Mañosa M, Cañete F et al (2021) Clinical considerations regarding the use of thiopurines in older patients with inflammatory Bowel disease. Drugs Aging 38:193-203

10. Instituto Nacional de Estadística. Equipo COVID-19 (2020) RENAVE. CNE. CNM (ISCII). Informe $n^{\circ} 27$. Situación de COVID-19 en España a 30 de abril de 2020. https://www.isciii. es/QueHacemos/Servicios/VigilanciaSaludPublicaRENAVE/ EnfermedadesTransmisibles/Documents/INFORMES/Infor mes\%20COVID-19/Informe\%20n\%c2\%ba\%2027.\%20Situaci\% c3\%b3n\%20de\%20COVID-19\%20en\%20Espa\%c3\%b1a\%20a\% 2030\%20de\%20abril\%20de\%202020.pdf. Accessed 09 Sep 2020

11. Instituto Nacional de Estadística (2020) Equipo COVID-19. RENAVE. CNE. CNM (ISCII). Informe $\mathrm{n}^{\circ} 74$. Situación de COVID-19 en España. Casos diagnosticados a partir de $10 \mathrm{de}$ mayo. https://www.isciii.es/QueHacemos/Servicios/Vigilancia SaludPublicaRENAVE/EnfermedadesTransmisibles/Documents/ INFORMES/Informes\%20COVID-19/INFORMES\%20COVID19\%202021/Informe\%20COVID-19.\%20N \% $2074 \_14 \% 20 \mathrm{de} \%$ 20abril\%20de\%202021.pdf. Accessed 26 Apr 2021

12. Agència de Qualitat I Avaluació Sanitària de Catalunya (AQuAS) (2021). https://aquas.gencat.cat/ca/actualitat/ultimes-dades-coron avirus/. Accessed 01 Mar 2021

13. Ungaro RC, Brenner EJ, Gearry RB et al (2021) Effect of IBD medications on COVID-19 outcomes: results from an international registry. Gut 70:725-732

14. Burke KE, Kochar B, Allegretti JR et al (2021) Immunosuppressive therapy and risk of COVID-19 infection in patients with inflammatory Bowel diseases. Inflamm Bowel Dis 27:155-161

15. Attauabi M, Poulsen A, Theede K et al (2021) Prevalence and outcomes of COVID-19 among patients with inflammatory Bowel disease: a Danish prospective population-based cohort study. J Crohns Colitis 15:540-550

Publisher's Note Springer Nature remains neutral with regard to jurisdictional claims in published maps and institutional affiliations. 